\title{
The Tagging Efficiency and Physiological Responses of Passive Integrated Transponder Tags in Black Rockfish, Sebastes schlegeli
}

\author{
In-Seok Park ${ }^{1 *}$, Jun Wook Hur ${ }^{2}$ and In Bon Goo ${ }^{3}$ \\ ${ }^{1}$ Division of Marine Bioscience, Korea Maritime \& Ocean University, Busan, Korea \\ ${ }^{2}$ Faculty of Marine Applied Biosciences, Kunsan National University, Kunsan, Korea \\ ${ }^{3}$ Corporate R\&D Center, Seojoonbio Inc., Daejeon, Korea
}

*Corresponding author: In-Seok Park, Division of Marine Bioscience, College of Ocean Science and Technology, Korea

Maritime \& Ocean University, Busan 49112, Korea

\section{ARTICLE INFO}

Received: 慧 February 20, 2020

Published: 仹 March 06, 2020

Citation: In-Seok Park, Jun Wook Hur. The Tagging Efficiency and Physiological Responses of Passive Integrated Transponder Tags in Black Rockfish, Sebastes schlegeli. Biomed J Sci \& Tech Res 26(3)-2020. BJSTR. MS.ID.004340.

\begin{abstract}
Passive integrated transponder (PIT) technology has been used for the identification of individual animals. PIT tags are inserted in the dorsal muscle, abdominal cavity, sham dorsal muscle, and sham abdominal cavity of the black rockfish, Sebastes schlegeli. During the experimental period, the tag retention rate and readability rate were greater in dorsal tags than in abdominal cavity tags in black rockfish $(P<0.05)$. Plasma cortisol and plasma glucose as indicators of stress were measured according to the passage of time after tagging. During $192 \mathrm{hrs}$, the tag insertion group showed higher plasma cortisol and plasma glucose levels compared to the sham group, and this similar pattern was seen in the abdominal cavity insertion group compared to the dorsal muscle insertion group $(P<0.05)$. While inserting PIT tags, stress can be minimized by insertion in the dorsal muscle of a fish.
\end{abstract}

Keywords: Blood Physiological Response; PIT tag; Plasma Cortisol; Plasma Glucose; Sebastes schlegeli

\section{Short Communication}

The black rockfish, Sebastes schlegeli (Hilgendorf), is an ovoviviparous marine fish that lives in rock areas of shallow coastal regions in all sea areas around Korea, Japan, and China [1]. In 1987, an artificial seed production technology of black rockfish was developed in Korea and came to get the spotlight when used as a cultured fish; its outturn increased rapidly when mass seed production became available [2,3]. The ability to identify individual animals is essential in fisheries research related to growth, migration, mortality, and stock identification in any species $[4,5]$. It is especially important that any such tagging system allows the identification to be made in a convenient, rapid, and non-lethal manner [6]. Tagging sites in a variety of body locations can be also successfully used. An example of a visual tag, which has been successfully applied on several fish species, is the Visible Implant Fluorescent Elastomer (VIFE) tag. VIFE tag system can identify the marked animals rapidly and it can't identify individuals, but it can identify affiliated experimental group of marked animals. Accordingly, the passive integrated transponder (PIT) tag is a suitable method. PIT tags have been used to study the behavior of small mammals, birds, invertebrates, reptiles, and amphibians since it was first used to monitor fish movement [7-9]. PIT tags are advantageous for studying animal behavior because they are small, inexpensive and can be kept effective for a long time and provide individual, unambiguous marks for tagged organisms $[9,10]$.

PIT tag method causes chronic stress condition by injection of PIT tag chip. Plasma cortisol and plasma glucose are recognized as useful indicators of stress in fish [11]. As expected, the plasma cortisol levels increased significantly at the beginning of chronic stress conditions [12], but then declined to their initial values thereafter [13]. [12] stated that "Usually, the phenomenon that plasma cortisol concentration of fishes rises by stress is the first-order reaction and the phenomenon that plasma glucose 
concentration rises by stress is the second-order reaction by hormone rise reaction caused by stress". Although PIT tags are used through insertion in the fish body, fish can be affected by its presence. The effects of these tags can differ in fish of different regions. Many fish species have transparent tissues that are suitable for tagging, including the abdominal cavity, head region, dorsal muscle, and tail muscle [10]. Sites suitable for retaining tags differ among species [10]. The aim of this study was to insert PIT tags into black rockfish of two regions in order to assess the stress that occurs in black rockfish through the insertion of PIT tags, and to investigate their physiological responses for determining the most suitable tagging site.

\section{Materials and Methods}

In September 2018, black rockfish, Sebastes schlegeli were obtained from black rockfish hatchery in Korea. The fish were transported and reared in the Fishery Genetics and Breeding Sciences Laboratory of the Korea Maritime \& Ocean University in Busan, Korea. Black rockfish used in the experiment were measured under anesthesia using a digital vernier caliper (CD-20CP, Japan) and an electronic balance (JW-1, Korea), and the average body length and average body weight were found to be $16.8 \pm 2.23 \mathrm{~cm}$ and $103.9 \pm 36.73$ g respectively.

The PIT tags used in this study were glass implantable transponders, $12.04 \mathrm{~mm}$ in length, $2.04 \mathrm{~mm}$ in diameter, and 88.4 mg in air (TX1400L, Biomark Inc., Idaho, USA). The populations were divided into three experimental groups: one in which a PIT tag was inserted in the dorsal muscle and another in which a PIT tag was inserted in the abdominal cavity, and a control group (Figure 1). Measurements were carried out every 1 month for 6 months (September 2018 to March 2019) on the same day of the month. Measurements, including body weight, standard length, survival rate, tag retention, and tag readability were recorded under anesthesia.

The populations were divided into five experimental groups: one in which a PIT tag was inserted in the dorsal muscle and another in which a PIT tag was inserted in the abdominal cavity, two sham groups in which each underwent pierce injection only, and a control group (Figure 1). Twenty-four fish were used for each group, except the control group, which was composed of five fish. The blood physiology response experiment began on January 2019. For the fish blood physiology response experiment, the food supply was disrupted $24 \mathrm{hrs}$ prior to sampling. A blood physiology response experiment of PIT tags for each tagging region was performed in water at a temperature of $20^{\circ} \mathrm{C}$. Blood samples were taken by sampling three fish at the same time from each group at intervals of $1,3,6,9,12,24,96$, and 192 hrs after tagging. The experiment was performed in triplicate. Blood was collected from the caudal vascuiature using a disposable syringe $(3 \mathrm{ml}$, Sung Shim Medical Co., Ltd, Korea) with heparin sodium (Shin Poong Pharm Co., Ltd, Korea) within 1 min.

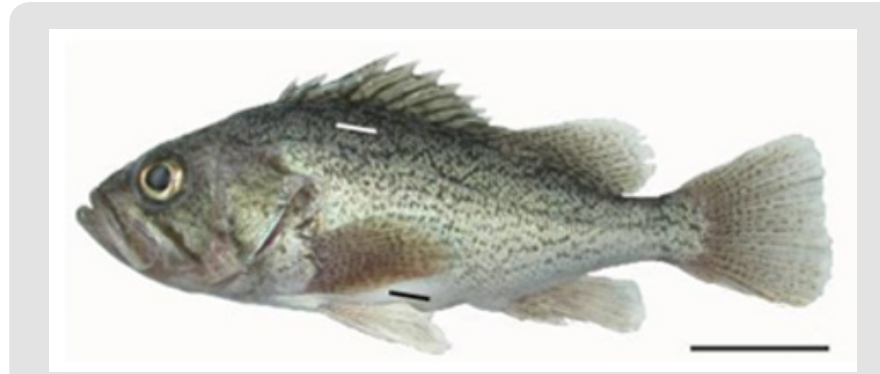

Figure 1: Insert positions of PIT tags in black rockfish, Sebastes schlegeli with marked white line (dorsal muscle) and black line (abdominal cavity). Scale bar is $2 \mathrm{~cm}$.

Blood sat for $10 \mathrm{~min}$ at normal temperature prior to centrifugation (Centrifuge Micro 17R, Hanil Science Industrial Co., Ltd, Korea) for $10 \mathrm{~min}$ at 15,000 rpm. The collected plasma was transferred to another $1.5 \mathrm{~mL}$ microtube and kept at $-70^{\circ} \mathrm{C}$ in a super low temperature refrigerator (CLN-50UW Nihon Freezer, Nihon Co., Japan) prior to analysis. The plasma cortisol concentration was measured using 1470 WIZARD Automatic Gamma Counter (Cobra, Packard Co., USA) after the antigen antibody response was derived using Coat-A-count TKCO Cortisol RIA Kit (DPC, USA) according to the [14] method. The plasma glucose concentration was analyzed using a Chemistry System (Hitachi 7180, Hitachi, Japan). The differences among groups were analyzed by one-way ANOVA using the SPSS Statistics Package (SPSS 9.0, SPSS Inc., USA), and multiple comparisons were performed using Duncan's multiple range test [15].

\section{Results}

During the experiment periods, no samples were died from the stress of syringe injection. (Table 1) lists the survival rates in each of the three experimental groups, as well as the tag retention and readability rates in black rockfish, Sebastes schlegeli tagged with PITs in the abdominal cavity or dorsal muscle. One month after tagging (September 2018), the tag retention rate of abdominal group was lower than dorsal group (October 2018), the survival rate was lower in the abdominal group than in the other groups. The tag retention rate was significantly lower in the abdominal group than in dorsal groups $(P<0.05)$. However, the tag readability rate was not significantly different among the experimental groups $(P>0.05)$. Two months after tagging, the survival rate was not significantly different among each group $(P>0.05)$. Although the cumulative retention rate of abdominal group was significantly lower than dorsal groups $(P<0.05)$, the tag readability rate was not significantly different among the three experimental groups. Three months after tagging, the survival rate in the abdominal group was significantly lower than the control group $(P<0.05)$. The trends in the tag retention and readability rates at 3 months were similar to those at 2 months.

As shown in Table 1, four months after tagging, the survival rate in the abdominal group was lower than the dorsal and control 
groups. The trends in tag retention and readability rates at 4 months were similar to those at 2 and 3 months. Five months after tagging, the survival rates were not significantly different among the experimental groups $(P>0.05)$. The cumulative retention rate of abdominal group was lower than that of dorsal groups. Six months after tagging, the trends in survival and tag retention rates were similar to those at 5 months. The tag retention and readability rates of abdominal group were lower than dorsal groups. The number of surviving fish, retained tags, and readable tags were the lowest in the abdominal group. The tag retention and readability rates in the dorsal group were significantly higher than those of abdominal groups throughout the experimental period.

Table 1: Survival rate and tags retention rate and readability of black rockfish, Sebastes schlegel tagged with PIT tags in the abdominal cavity, dorsal muscle, and untagged control groups.

\begin{tabular}{|c|c|c|c|c|}
\hline \multirow{2}{*}{$\begin{array}{l}\text { Time After } \\
\text { Tagged } \\
\text { (month) }\end{array}$} & \multirow{2}{*}{$\begin{array}{c}\text { Exp. } \\
\text { Group* }\end{array}$} & \multicolumn{3}{|c|}{ Variables** } \\
\hline & & Survival Rate (\%) & Tags Retention rate (\%) & Tags Readability (\%) \\
\hline \multirow{3}{*}{$\begin{array}{c}0 \\
\text { (Sep., 2018) }\end{array}$} & $\mathrm{CN}$ & 100 & - & - \\
\hline & $\mathrm{DM}$ & 100 & 96.7 & 100 \\
\hline & $\mathrm{AC}$ & 100 & 93.3 & 100 \\
\hline \multirow{3}{*}{$\begin{array}{c}1 \\
\text { (Oct., 2018) }\end{array}$} & $\mathrm{CN}$ & $98.3 \pm 1.91^{\mathrm{a}}$ & - & - \\
\hline & DM & $100 \pm 0.00^{\mathrm{a}}$ & 100 & 100 \\
\hline & AC & $98.3 \pm 1.87^{\mathrm{a}}$ & 100 & 100 \\
\hline \multirow{3}{*}{$\begin{array}{c}2 \\
\text { (Nov., 2018) }\end{array}$} & $\mathrm{CN}$ & $98.3 \pm 1.01^{\mathrm{a}}$ & - & - \\
\hline & DM & $98.3 \pm 1.42^{\mathrm{a}}$ & 100 & 100 \\
\hline & $\mathrm{AC}$ & $98.2 \pm 1.35^{\mathrm{a}}$ & 100 & 100 \\
\hline \multirow{3}{*}{$\begin{array}{c}3 \\
\text { (Dec., 2018) }\end{array}$} & $\mathrm{CN}$ & $100 \pm 0.00^{\mathrm{a}}$ & - & - \\
\hline & $\mathrm{DM}$ & $98.2 \pm 1.82^{\mathrm{b}}$ & 100 & 100 \\
\hline & AC & $96.3 \pm 1.47^{\mathrm{b}}$ & 100 & 100 \\
\hline \multirow{3}{*}{$\begin{array}{c}4 \\
\text { (Jan., 2019) }\end{array}$} & $\mathrm{CN}$ & $100 \pm 0.00^{\mathrm{a}}$ & - & - \\
\hline & $\mathrm{DM}$ & $100 \pm 0.00^{\mathrm{a}}$ & 100 & 100 \\
\hline & $\mathrm{AC}$ & $98.1 \pm 1.18^{\mathrm{b}}$ & 100 & 100 \\
\hline \multirow{3}{*}{$\begin{array}{c}5 \\
\text { (Feb., 2019) }\end{array}$} & $\mathrm{CN}$ & 100 & - & - \\
\hline & $\mathrm{DM}$ & 100 & 100 & 100 \\
\hline & $\mathrm{AC}$ & 100 & 100 & 100 \\
\hline \multirow{3}{*}{$\begin{array}{c}6 \\
\text { (Mar., 2019) }\end{array}$} & $\mathrm{CN}$ & 100 & - & - \\
\hline & $\mathrm{DM}$ & 100 & 100 & 100 \\
\hline & $\mathrm{AC}$ & 100 & 100 & 100 \\
\hline
\end{tabular}

The plasma cortisol and plasma glucose concentration in black rockfish from each tagging region are shown in (Figures 2 \& 3). The plasma cortisol concentration of fish was $4.78 \pm 0.412 \mu \mathrm{g} /$ $\mathrm{dL}$ at the beginning of the experiment. As shown in (Figure 2a \& $2 \mathrm{~b}$ ), the plasma cortisol concentration tended to be increased with the passage of time after tagging at 1 and $3 \mathrm{hrs}$, and the control also showed a similar tendency after $6 \mathrm{hrs}$. From the results that compared the four experimental groups at each time, the groups in which a tag had been inserted generally showed higher values at 1 and $3 \mathrm{hrs}$ compared to the sham groups $(P<0.05)$, and the abdominal cavity insertion group generally displayed higher values than the dorsal muscle insertion group at 3,6, and $12 \mathrm{hrs}(P<0.05)$.
As shown in (Figures 3a \& 3b), the plasma glucose concentration of fish was $53.2 \pm 8.67 \mathrm{mg} / \mathrm{dL}$ at the beginning of the experiment. The plasma cortisol concentration tended to be increased with the passage of time after tagging at $1 \mathrm{hr}$, and decreased from $6 \mathrm{hrs}$; the control group showed a similar tendency after $12 \mathrm{hrs}$. From the results that compared the four experimental groups in each time, groups in which a tag had been inserted generally displayed higher values at 1, 3 and 9 hrs compared to the sham groups $(\mathrm{P}<0.05)$, and the abdominal cavity insertion group generally displayed higher values than the dorsal muscle insertion group at 1,3 and 6 hrs $(P$ $<0.05$ ). 

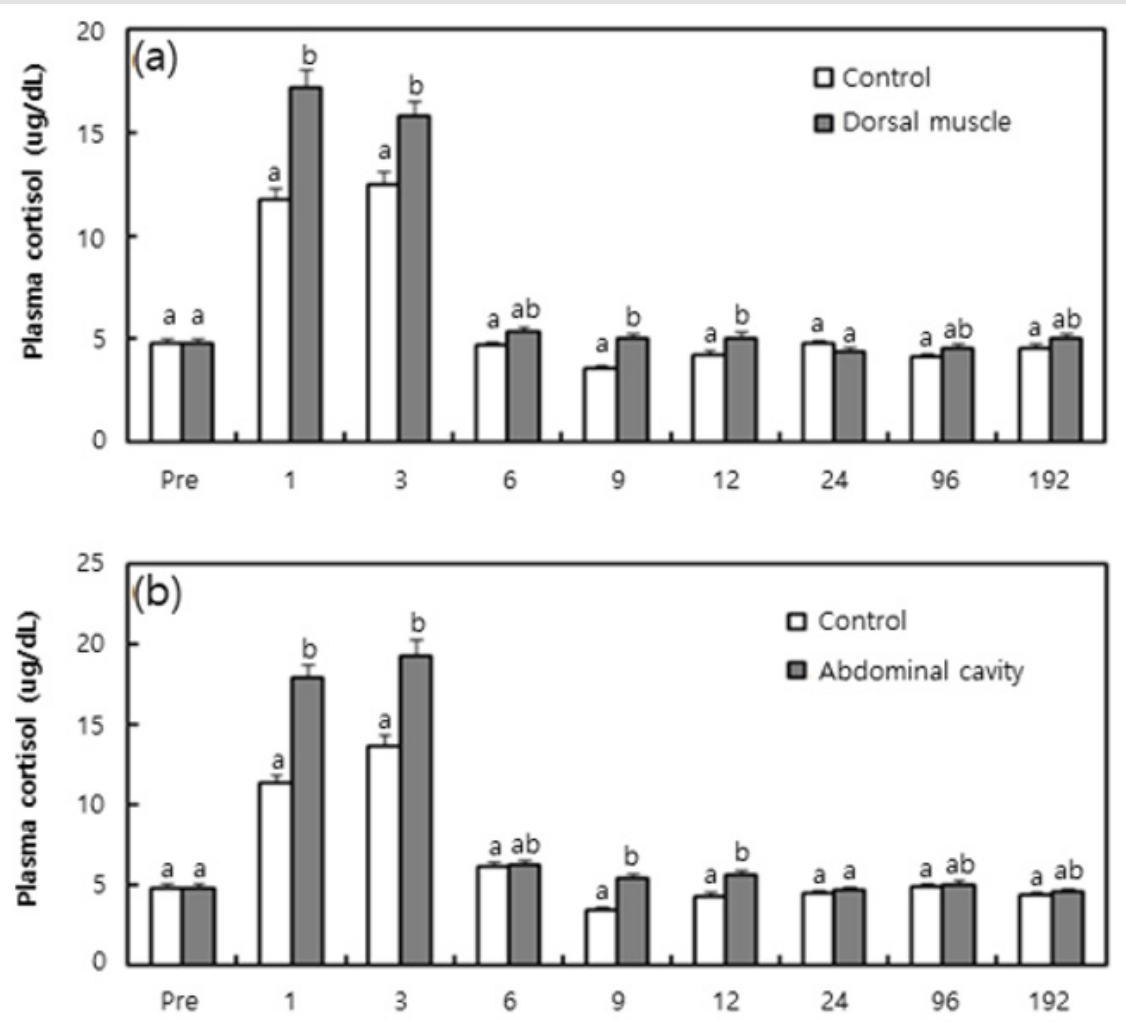

Figure 2: Plasma glucose measurements of black rockfish, Sebastes schlegeli, and measured responses to the positions of PIT tags from 1 to 192 hrs, in addition to the control group: a) Dorsal muscle; b) Abdominal cavity. Values (means of triplicate \pm SD) having different superscript letter are significantly different for groups at each elapsed time $(P<0.05)$.
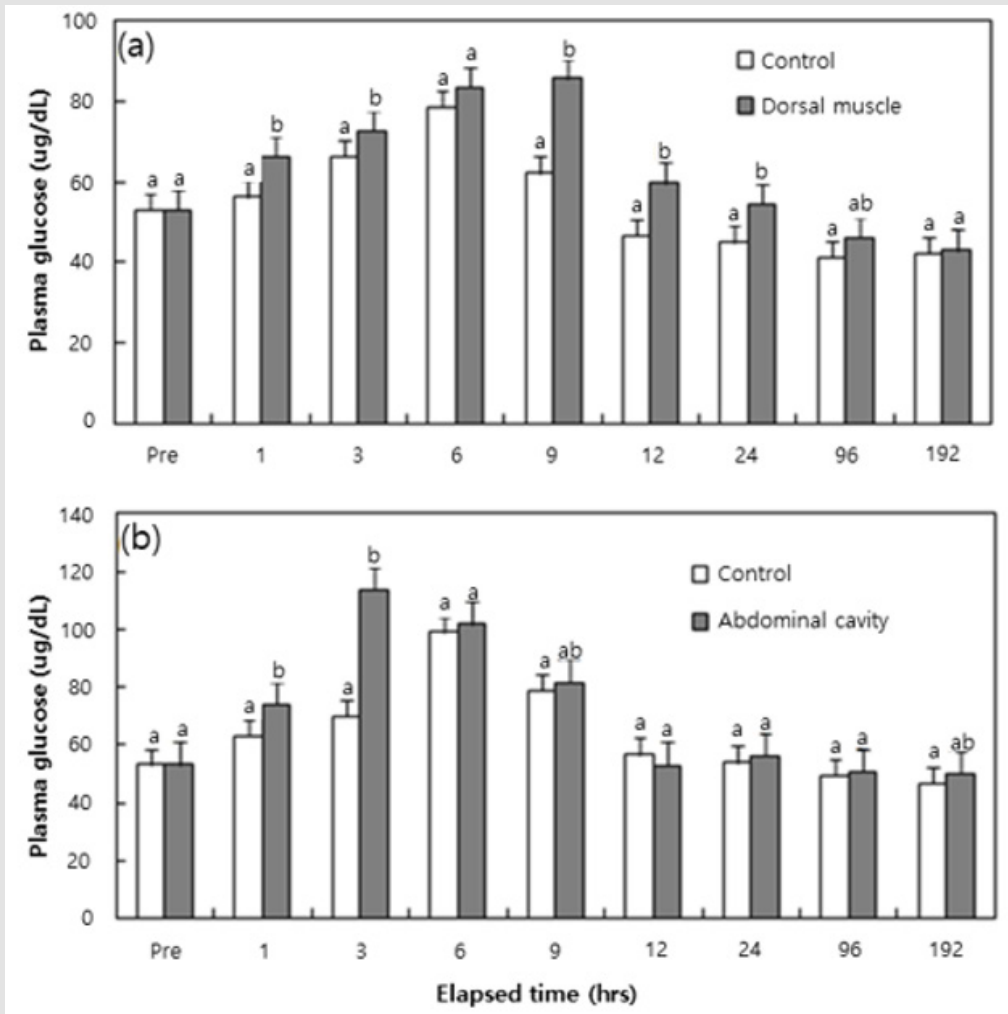

Figure 3: Plasma glucose measurements of black rockfish, Sebastes schlegeli, and measured responses to the positions of PIT tags from 1 to 192 hrs, in addition to the control group: a) Dorsal muscle; b) Abdominal cavity. Values (means of triplicate \pm SD) having different superscript letter are significantly different for groups at each elapsed time $(P<0.05)$. 


\section{Discussion}

Implanted tags caused no internal damage, presumably because their midventral location prevented most contacts with organs and dissipated the risk of erosion. The encapsulation of most tags by host tissue and the resulting limited migration of tags inside the cavity may also added to the reduction of this risk [16,17]. [18]'s study has demonstrated that PIT tagging in the abdominal cavity and the dorsal muscle in kelp grouper, Epinephelus bruneus has the potential to reliably identify individuals and is associated with high tag retention rates, readability and fish survival. Although mass gain of the dorsal muscle tagged group was slightly lower than in the abdominal cavity tagged group, no difference was established in all other factors. Based on the criteria and variables outlined in [18]'s study, the use of PIT tagging in the abdominal cavity of kelp grouper is advocated as a practical and reliable method for fish identification and monitoring, without negative effects on growth and mortality. However, foreign materials such as tags can lead to stress, and may cause changes of the blood reactions of fish. When stress is induced, fish consume energy, which drives a response of excess secretion of catecholamine and cortisol and has a considerable influence on the maintenance of homeostasis [12,19-21].

Plasma cortisol and plasma glucose are recognized as useful indicators of stress in fish [11]. Notable increases in plasma cortisol and plasma glucose levels were reported in the black rockfish, Sebastes schlegeli, after exposure to MS-222 and lidocaine- $\mathrm{HCl}$ anesthetic [22]. In this study, blood physiology responses of black rockfish from each tagging region, in the form of high plasma cortisol and plasma glucose values, was generally observed in the groups in which a tag had actually been inserted compared to the responses seen in sham groups. This finding indicates that the actual insertion of a tag rather than just a pierce injection can result in added stress. In addition, the group in which a tag had been inserted in the abdominal cavity generally showed higher plasma cortisol and plasma glucose values than the group in which tags had been inserted in the dorsal muscle. This result shows that greater stress results from the insertion of a tag into the abdominal cavity, where internal organs exist, than in the dorsal muscle, which is distributed under the flesh.

The plasma cortisol levels induced by stress appear to increase at various speed and time according to the species of fish [12]. The plasma cortisol concentration after stress is usually reported to increase to a peak value within $1 \sim 3 \mathrm{hrs}$, and normally recovers within 6 hrs [23]. As a whole, plasma cortisol and plasma glucose values in the sham groups and the groups in which tags had been inserted were similar to the values seen in the control group after $6 \mathrm{hrs}$. Therefore, the time required for the black rock fish to adapt after the insertion of a tag is approximately $6 \mathrm{hrs}$. Also, the plasma cortisol and plasma glucose concentrations showed peak values before $6 \mathrm{hrs}$ in this study; these values agree with those reported by [23]. The trends in cortisol and glucose observed in this experiment indicated generalized stress reactions. Glucose formation was increased simultaneously as the cortisol quantity increased. Elevated cortisol secretion under stress increases the activation of plasma glucose by activity of the gluconeogenesis enzyme and this increase is also the result of a second reaction to the first reaction (response of hormone) to stress [12,24].

In this study, groups in which a tag was inserted suffered from more stress than the sham groups. In addition, the group in which a tag was inserted in the abdominal cavity suffered from less stress than the group that experienced insertion of a tag in the dorsal muscle, but this difference was fairly minor. Therefore, the insertion of PIT tags into the dorsal muscles of fish will minimize stress compared to other sites of insertion. This study examined the most suitable site for the stress responses by PIT tags. As mentioned by $[9,25]$, the tissue reaction to the implanted tag included an increased abundance of fibroblasts in the fibrous capsule, which represents chronic inflammation rather than acute inflammation. So, future investigation needs to be focused on determining the most suitable site by the histological responses to PIT tags which were inserted into two sites in this species.

\section{Conclusion}

A variety of tagging products have been tried depending on the tagging aim. The passive integrated transponder (PIT) tag, have been shown to be a reliable and effective method for identification and monitoring $[9,26,27]$ as well showing little or no effect on fish growth and survival $[10,28]$. The effects of PIT tags inserted in the dorsal muscle, abdominal cavity, sham dorsal muscle, and sham abdomind cavity of the black rockfish, Sebastes schlegeli on the tag retension rate, readability rate and physiological responses (plasma cortisol and plasma glucose as indicators of stress) was examined for 6 months. During the experimental period, the tag retension rate and readability rate were greater in dorsal tags than in abdominal cavity tags in black rockfish. While inserting PIT tags, stress can be minimized by insertion in the dorsal muscle of a fish.

\section{Declaration}

\section{Ethics Approval and Consent to Participate}

The experiments performed in this study complied with the current laws of Korea (Ordinance of Agriculture, Food and Fisheries, No. 1 - the law regarding experimental animals, No. 9982) and the Ethical Guidelines of Korea Maritime \& Ocean University, Korea.

\section{Acknowledgement}

I am grateful to the staff of the Fishery Genetics and Breeding Sciences Laboratory of the Korea Maritime \& Ocean University, Korea. The author would like to thank anonymous reviewers for their helpful suggestions that improved the quality of this paper.

\section{Conflict of Interests}

The author has no financial or personal conflicts of interests. 


\section{References}

1. Choi Y, Kim JH, Park JY (2002) Marine fishes of Korea. Kyo-Hak Publi, Seoul, South Korea, p. 47-50.

2. Kim SG, Ko CS, Song CH (1987) Mass production and technical development of mariculture seeding. Bull Nat Fish Res Dev Agency 71 117-122.

3. (2015) KOSIS, Korean Statistical Information Service. Retrieved from Kosis.

4. Konstantinov KG (1978) Modern methods of fish tagging. J Ichthyol 17: 924-938.

5. Park IS, Lee KK (2001) The effective location of visible implant tags for short-term marking in Nile tilapia (Oreochromis niloticus: Cichlidae). J Fish Sci Tech 4: 159-161.

6. Thomas C, Stephen AS, Yhomas ET, Robert BD, Shawn CW, et al. (1999) Identification of individual prawns with implanted microchip transponders. Aquaculture 180(1-2): 41-51.

7. Prentice EF, Flagg TA, Mc Cutcheon CS, Brastow DF (1990) PIT-tag monitoring systems for hydroelectric dams and fish hatcheries. Am Fish Soc Symp 7: 317-322.

8. Gibbons JW, Andrews KM (2004) PIT tagging: Simple technology at its best. Bioscience 54: 447-454.

9. Gil HW, Goo IB, Park IS (2017) Long-term effects of passive integrated transponder tags in far eastern catfish, Silurus asotus. Aquacult Eng 79: 17-23.

10. Lee JH, Park IS, Cho SH (2009) Long-term effects of passive integrated transponder tagging on the growth of olive flounder, Paralichthys olivaceus. J World Aquacult Soc 40: 134-139.

11. Schreck CB (1982) Stress and rearing of salmonids. Aquaculture 28: 241-249.

12. Barton BA, Iwama GK (1991) Physiological changes in fish from stress in aquaculture with emphasis on the response and effects of corticosteroids. Ann Rev Fish Dis 1: 3-26.

13. Tort L, Gomez E, Montero D, Sunyer JO (1996) Serum haemolytic and agglutinating activity as indicators of fish immunocompetence: Their suitability in stress and dietary studies. Aquacult Int 4: 31-41.

14. Donaldson EM (1981) The pituitary-internal axis as an indicator of stress in fish, In: Pickering AD (Eds.)., Stress in Fish, Academic Press, London, UK. p. 11-47.

15. Duncan DB (1955) Multiple-range and multiple F tests. Biometrics 1: $1-42$.

ISSN: 2574-1241

DOI: $10.26717 /$ BJSTR.2020.26.004340

In-Seok Park. Biomed J Sci \& Tech Res

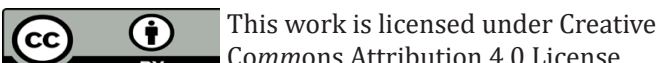

Submission Link: https://biomedres.us/submit-manuscript.php
16. Pedersen BH, Andersen NG (1985) A surgical method for implanting transmitters with sensors into the body cavity of the cod (Gadus morhua L.). Dana 5: 55-62.

17. Lucas MC (1989) Effects of implanted dummy transmitters on mortality, growth and tissue reaction in rainbow trout, Salmo gairdneri Richardson. J Fish Biol 35: 577-587.

18. Park MO, Park IS (2009) Long-term effects of passive integrated transponder (PIT) tagging on the kelp grouper Epinephelus bruneus. J Fish Biol 74: 285-288.

19. Clarke WC, Shelboune JR, Brett JR (1981) Effects of artificial photoperiod cycles, temperature and salinity on growth and smolting in under yearling coho (Oncorhynchus kisutch), chinook (O. tshawytscha), and sockeye (O. nerka) salmon. Aquaculture 22: 105-116.

20. Pickering AD (1992) Rainbow trout husbandry: management of the stress response. Aquaculture 100: 125-139.

21. Pickering AD (1993) Growth and stress in fish production. Aquaculture 111: 51-63.

22. Kim JH, Hur JW, Park IS, Kho KH, Chang YJ, et al. (2005) Effects of the different anesthetic doses of MS-222 and lidocaine-HCl on the blood physiological responses in black rockfish, Sebastes schlegeli. J Aquaculture 18: 236-244.

23. Pickering AD, Pottinger TG (1989) Stress responses and disease resistance in salmonid fish: Effects of chronic elevation of plasma cortisol. Fish Physiol Biochem 7: 253-258.

24. Park MO, Im SY, Seol DW, Park IS (2009) Efficacy and physiological responses of rock bream (Oplegnathus fasciatus) to anesthetization with clove oil. Aquaculture 287: 427-430.

25. Marty GD, Summerfelt RC (1988) Inflammatory response of channel catfish to abdominal implants: A histological and ultrastructural study. Trans Am Fish Soc 117: 401-416.

26. Pirhonen J, Valkeajärvi P, Thorpe JE, Soivio A (2003) Effect of stocking time on yield and location of recapture in two forms of brown trout (Salmo trutta) when stocked in respect to migration activity. Aquaculture 222: 189-201.

27. Navarro A, Oliva V, Zamorano MJ, Ginés R, Izquierdo MS, et al. (2006) Evaluation of PIT system as a method to tag fingerlings of gilthead seabream (Sparus auratus L.): effects on growth, mortality and tag loss. Aquaculture 257: 309-315.

28. Quartararo N, Bell JD (1992) Effect of intraperitoneal passive implantable transponder (PI) tags on the growth and survival of juvenile snapper, Pagrus auratus (Bloch and Schneider). Aquacult Fish Manag 23: 543548.

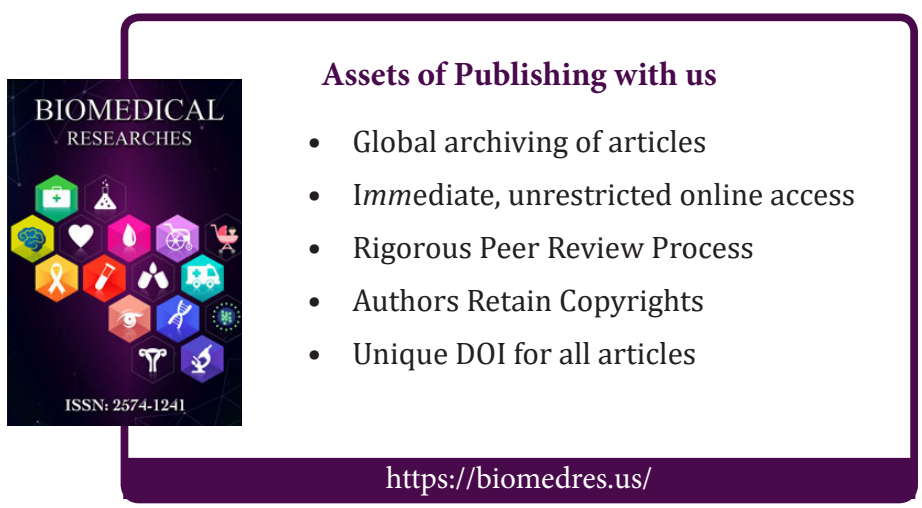

